\title{
Why the (dis)agreement? Family context and child-parent perspectives on health-related quality of life and psychological problems in pediatric asthma
}

\author{
Neuza Silva $•$ Carla Crespo $•$ Carlos Carona $•$ Monika Bullinger $•$ Maria Cristina Canavarro
}

\begin{abstract}
Introduction. Children's health-related quality of life (HrQoL) and psychological problems are important outcomes to consider in clinical decision making in pediatric asthma. However, children's and parents' reports often differ. The present study aimed to examine the levels of agreement/disagreement between children's and parents' reports of HrQoL and psychological problems and to identify socio-demographic, clinical and family variables associated with the extent and direction of (dis)agreement. Method. The sample comprised 279 dyads of Portuguese children with asthma who were between 8 and 18 years of age $(M=12.13 ; S D=2.56)$ and one of their parents. The participants completed self- and proxy-reported questionnaires on pediatric generic HrQoL (KIDSCREEN-I0), chronic-generic HrQoL (DISABKIDS-37) and psychological problems (Strengths and Difficulties Questionnaire). Children's and parents' perceptions of family relationships were measured with the Family Environment Scale and the caregiving burden was assessed using the Revised Burden Measure.

Results. The child-parent agreement on reported HrQoL and psychological problems was poor to moderate (intraclass correlation coefficients between .32 and .47). The rates of child-parent discrepancies ranged between 52.7\% (psychological problems) and 68.8\% (generic HrQoL), with $50.5 \%$ and $31.5 \%$ of the parents reporting worse generic and chronic-generic HrQoL, respectively, and $33.3 \%$ reporting more psychological problems than their children. The extent and direction of disagreement were better explained by family factors than by socio-demographic and clinical variables: a greater caregiving burden was associated with increased discrepancies in both directions and children's and parents' perceptions of less positive family relationships were associated with discrepancies in different directions. Conclusion. Routine assessment of pediatric HrQoL and psychological problems in healthcare and research contexts should include self- and parent-reported data as complementary sources of information, and also consider the family context. The additional cost of conducting a more in-depth assessment of pediatric adaptation outcomes can be offset through more efficient allocation of health resources.
\end{abstract}

\section{Keywords}

Caregiving burden $\bullet$ Child-parent (dis)agreement $•$ Family relationships $•$ Health-related quality of life - Pediatric asthma - Psychological problems 


\section{Introduction}

Health-related quality of life $(\mathrm{HrQoL})$ and psychological problems have emerged as important health outcomes to consider in clinical decision making and research related to pediatric chronic conditions, such as asthma, because managing symptoms and improving psychosocial adaptation are now the primary goals of interventions (Clarke \& Eiser, 2004; Le Coq, Boeke, Bezemer, Colland, \& van Eijk, 2000). The assessment of pediatric populations poses particular methodological challenges, namely the reliability of children's self-reports and the advantages/disadvantages of using their parents as proxies (Bullinger, Schmidt, Peterson, \& RavensSieberer, 2006; Matza, Swensen, Flood, Secnik, \& Leidy, 2004). Parents' reports are essential when children are too young or unable to report their own experiences (Eiser \& Morse, 200I; Wallander, Schmitt, \& Koot, 200I), and these reports play an important role in decision making about treatment and healthcare use (Annett, Bender, DuHamel, \& Lapidus, 2003; Matza et al., 2004) and in detecting clinical changes over time (Le Coq et al., 2000). Nevertheless, the World Health Organization (WHO, 1993) recommends assessing children's individual perceptions of their quality of life (QoL) whenever possible. In addition, children's reports are more sensitive than their parents' in detecting minor emotional and behavioral disturbances (Becker, Hagenberg, Roessner, Woerner, \& Rothenberger, 2004; Van Roy, Groholt, Heyerdahl, \& Clench-Aas, 2010). Therefore, a multiinformant approach that includes both children's and parents' reports has been widely recommended to enable a comprehensive assessment of pediatric adaptation outcomes (Eiser \& Morse, 200I; Van Roy et al., 2010).

Over the last few years, several instruments with self- and proxy-reported forms for assessing pediatric HrQoL and psychological problems have been developed (Bullinger et al., 2006; Goodman, 200I). Despite the common assumption that the reports from children and parents should be similar, most studies have found low to moderate levels of agreement on HrQoL (e.g., Sattoe, van Staa, Moll, \& On Your Own Feet Research Group, 2012; White-Koning et al., 2007) and psychological problems (e.g., Ender, Stachow, Petermann, \& Tiedjen, 20I I; Van der Meer, Dixon, \& Rose, 2008), with lower rates for social and emotional domains than for physical symptoms and observed behaviors (Becker et al., 2004; Eiser \& Morse, 200I).

Children's health status seems to impact both the degree to which children and parents agree/disagree [the extent of (dis)agreement] and whether parents are more likely to over or underrate pediatric HrQoL and psychological problems (the direction of disagreement). Higher levels of agreement have been reported between parents and children with chronic conditions, compared with healthy controls (Russell, Hudson, Long, \& Phipps, 2006). Research on pediatric chronic conditions has found that parents reported significantly lower HrQoL (Sattoe et al., 2012; White-Koning et al., 2007) and more psychological problems (Becker et al., 2004) than the children 
themselves, which is the opposite of the directional pattern of disagreement found in the general population (Cremeens, Eiser, \& Blades, 2006; Gaspar, Matos, Batista-Foguet, Pais-Ribeiro, \& Leal, 2010; Sawyer, Baghurst, \& Mathias, 1992; Theunissen et al., 1998). Moreover, Upton, Lawford, and Eiser, (2008) stated that the levels of agreement would also depend on the relevance of different domains for a specific clinical group because parents would be most alert to the frailest domains of their children's HrQoL. This argument is supported by research that shows positive associations between the extent of agreement and disease severity and length (April, Feldman, Platt, \& Duffy, 2006; Petsios et al., 20I I).

Children's developmental characteristics have also been investigated in the child-parent (dis)agreement research, which has produced inconsistent findings to date. Some studies have found higher levels of agreement for older children, supporting the hypothesis that the levels of agreement depend on cognitive and communication skills (e.g., Petsios et al., 20I I). Conversely, other studies have described greater agreement between parents and younger children, suggesting that increasing independence in adolescence may limit the sharing of experiences with parents (e.g., April et al., 2006; Jokovic, Locker, \& Guyatt, 2004). Children's and parents' genders have also been suggested as important determinants of (dis)agreement (Eiser \& Morse, 200I; Upton et al., 2008); however, few empirical studies have addressed the role of these variables (e.g., Theunissen et al., 1998) and no clear findings have emerged.

The examination of family-related factors remains an important gap in (dis)agreement research in general and in pediatric asthma in particular. There is, nonetheless, some evidence suggesting that the study of family relationships may add valuable contributions to our current understanding of the extent and direction of child-parent (dis)agreement (De Civita et al., 2005). For example, White-Koning and colleagues (2007) described a significant association between higher levels of parenting stress and parents' underrating the HrQoL of their children with cerebral palsy. Family relationships characterized by poor parental engagement and communication have also been linked to an increased likelihood of disagreement on reports of emotional and behavioral problems, most often with children reporting more problems than their parents (Van Roy et al., 2010). In addition, in a pediatric asthma study, the illness-related burdens experienced by parents were negatively associated with parents' reports of pediatric HrQoL (Annett et al., 2003), which may contribute to child-parent disagreement.

In the context of pediatric asthma, the present study aimed to examine the (dis)agreement between child- and parent-reported adaptation outcomes (HrQoL and psychological problems) and to identify the socio-demographic, clinical and family variables that may account for the extent and direction of disagreement. Three hypotheses were formulated: $(\mathrm{HI})$ child-parent agreement on reports of adaptation outcomes will be moderate; $(\mathrm{H} 2)$ parents will report lower HrQoL and more psychological problems than children; $(\mathrm{H} 3)$ the extent of disagreement, particularly in parents' 
underrating of adaptation outcomes, will be associated with the clinical characteristics of their child's asthma (i.e., lower severity and a shorter time since diagnosis), with less positive family relationships and with greater caregiving burden.

\section{Method}

\section{Participants and procedure}

The participants (279 dyads of children with asthma and one of their parents) were enrolled between March 2010 and February 2012 in the outpatient services of three Portuguese public hospitals (Coimbra University Hospitals, Coimbra Pediatric Hospital and Leiria Saint Andre Hospital) after the study had been approved by the institutions' ethic committees. Using a non-probabilistic convenience sampling method, the children were selected based on their medical files, according to the following criteria: (I) age between 8 and 18 years; (2) diagnosis of asthma according to the International Classification of Disease (ICD-I0) for at least I year; (3) absence of other chronic conditions; and (4) accompanied by the parent self-identified as the primary caregiver. The participants' socio-demographic and clinical characteristics are presented in Table I.

Table I | Socio-demographic and clinical characteristics of the sample

\begin{tabular}{|c|c|c|}
\hline & $\begin{array}{l}\text { Children } \\
(n=279)\end{array}$ & $\begin{array}{l}\text { Parents } \\
(n=279)\end{array}$ \\
\hline \multicolumn{3}{|c|}{ Socio-demographic characteristics } \\
\hline Age (in years), $M(S D)$ & $12.13(2.56)$ & $4 I .33(5.90)$ \\
\hline \multicolumn{3}{|l|}{ Age group ${ }^{a}, n(\%)$} \\
\hline Children & $162(58.1 \%)$ & \\
\hline Adolescents & 117 (4I.9\%) & \\
\hline \multicolumn{3}{|l|}{ Gender, $n(\%)$} \\
\hline Male & $175(62.7 \%)$ & $4 \mathrm{I}(14.7 \%)$ \\
\hline Female & $104(37.3 \%)$ & $238(85.3 \%)$ \\
\hline \multicolumn{3}{|c|}{ Socio-economic level ${ }^{\mathrm{b}}, n(\%)$} \\
\hline Low & & $168(60.2 \%)$ \\
\hline Medium & & $78(28.0 \%)$ \\
\hline High & & $20(7.2 \%)$ \\
\hline Missing & & $13(4.7 \%)$ \\
\hline
\end{tabular}

\footnotetext{
a The pediatric sample was divided into two age groups based on The DISABKIDS Group Europe's (2006) categories: children (8-12 years old) and adolescents (13-18 years old). For simplicity, we adopted the term children to refer to the pediatric sample, which includes both age groups. ${ }^{\text {b Socio- }}$ economic level was determined using a classification system for the Portuguese context based on the parents' jobs and educational levels (Simões, 1994).
} 
Table I | Socio-demographic and clinical characteristics of the sample (cont.)

\begin{tabular}{|c|c|c|}
\hline & Children & Parents \\
\hline \multicolumn{3}{|l|}{ Clinical characteristics } \\
\hline \multicolumn{3}{|l|}{ Asthma severity ${ }^{c}, n(\%)$} \\
\hline Intermittent & I 57 (56.3\%) & \\
\hline Mild persistent & $73(26.2 \%)$ & \\
\hline Moderate persistent & $4 \mid(\mid 4.7 \%)$ & \\
\hline Severe persistent & $8(2.9 \%)$ & \\
\hline Age (in years) at the time of diagnosis, $M(S D)$ & $4.74(3.89)$ & \\
\hline Time (in years) since asthma diagnosis, $M(S D)$ & $7.64(4.04)$ & \\
\hline Using medication, $n(\%)$ & $273(97.8 \%)$ & \\
\hline
\end{tabular}

'Asthma severity was classified by physicians, according to the Global Initiative for Asthma [GINA] (2008) guidelines. Due to the heterogeneous distribution of asthma severity in our sample, this variable was dichotomized and dummy-coded $[0$ - intermittent asthma, $n=157$; I - persistent asthma (mild, moderate and severe), $n=122]$.

The pediatric sample was mainly composed of boys and most of the children had intermittent asthma, which is consistent with the prevalence of asthma by gender and with the distribution of asthma severity levels typically observed in the Portuguese pediatric population (Gaspar, Almeida, \& Nunes, 2006). The great majority of caregivers was female and had low/medium socio-economic status, reflecting the users' profile in public pediatric healthcare services in Portugal.

Informed consent was obtained from all parents and adolescents older than 13 years, and informal assent was obtained from younger children. The protocols were completed by the children and parents in the health institution they attended, under the supervision of a trained research assistant who ensured that no information was exchanged between the children and their parents.

\section{Measures}

\section{Children's adaptation outcomes}

The children's HrQoL was measured by the Portuguese self- and proxy-reported versions of the KIDSCREEN-10 Index (Ravens-Sieberer et al., 2010; Portuguese version: Matos, Gaspar, \& Simões, 2012) and the DISABKIDS-37 Chronic-Generic Module (The DISABKIDS Group Europe, 2006; Portuguese version: Carona et al., 2013). The KIDSCREEN-10 provides a general index of subjective health and well-being, whereas the DISABKIDS-37 assesses the impact of the chronic condition on six facets of the children's QoL: Independence, Emotion, Social inclusion, Social exclusion, Physical limitation and Treatment. Both questionnaires were answered using a five-point Likert scale ranging from I (never) to 5 (always), with higher scores indicating better HrQoL.

Psychological problems were assessed using the Difficulties scale of the Portuguese self- and parent-rated versions of the Strengths and Difficulties Questionnaire (Goodman, 200I; Portuguese version: Fleitlich, Loureiro, Fonseca, Gaspar, 2005). This scale comprises 20 items that were 
clustered into Internalizing and Externalizing problems (Goodman, Lamping, \& Ploubidis, 2010) and answered using a Likert-type response scale with three options $(0=$ not true, I = somewhat true and $2=$ certainly true). Higher values indicated more psychological problems. The Cronbach's alpha values found in our sample for each measure are presented in Table 2.

\section{Family variables}

The overall quality of family relationships was assessed by the children and parents using the Portuguese version of the Family Relationships Index (Moos, 1990). This scale is comprised of the Cohesion, Expressiveness and Conflict dimensions of the Family Environment Scale (Moos \& Moos, 1986), which assess how involved family members are in their family and how openly they express both positive and negative feelings, using 27 items scored on a six-point Likert scale ranging from I (completely disagree) to 6 (completely agree), with higher scores indicating better perceived family relationships. In the current sample, the Cronbach's alpha values were .86 and .85 for children's and parents' reports, respectively.

The caregiving burden was measured using the Portuguese version of the Revised Burden Measure (Montgomery \& Kosloski, 2006; Portuguese version: Carona, Silva, \& Canavarro, 20II). This scale assesses the parents' perceptions of changes in dyadic parent-child relationships (Relationship burden), time constraints resulting from caregiving activities (Objective burden) and generalized negative affect (Subjective burden), with 16 items scored on a five-point Likert scale ranging from I (not at all) to 5 (a great deal), with higher values indicating a greater caregiving burden. Good internal consistency was observed for our sample (Cronbach's alpha $=.93$ ).

\section{Statistical analyses}

Statistical analyses were performed with SPSS 17.0 (SPSS Inc., Chicago, IL, USA). The childparent (dis)agreement on adaptation outcomes was examined at the individual and the group levels (Sneeuw, Sprangers, \& Aaronson, 2002), by using, respectively, intraclass correlation coefficients (ICC) [two-way mixed model, absolute agreement, 95\% confidence interval (Cl)] and analyses of covariance for repeated measures (univariate analyses for the total scores and multivariate analyses for the six facets of chronic-generic HrQoL and for the two dimensions of psychological problems). Absolute and directional discrepancies were computed as dyadic indexes of the extent and direction of disagreement, respectively (Kenny, Kashy, \& Cook, 2006). Directional discrepancies were categorized into three groups ("child-report > parent-report", "agreement" and "child-report < parent-report") based on the threshold for clinically important differences in QoL (Norman, Sloan, \& Wyrwich, 2003). Thus, agreement was defined as an absolute child-parent difference that was lower than or equal to half of the standard deviation (SD) of the score with the greatest variability. In order 
to identify the clinical, socio-demographic and family-related variables associated with the extent and direction of child-parent discrepancies, hierarchical multiple regression analyses and multinomial logistic regression analyses using "agreement" as the reference category were respectively performed (Field, 2009). For multinomial logistic regressions, the goodness-of-fit of the overall model was evaluated using likelihood ratio tests and the statistical significance of individual predictors was evaluated by calculating the Wald statistic and the odds ratio (OR) with a $95 \% \mathrm{Cl}$.

\section{Results}

Child-parent (dis)agreement

At the individual level, there were poor to moderate correlations between children's and parents' reports of pediatric HrQoL and psychological problems (Table 2). At the group level, after controlling for socio-demographic and clinical variables, the results indicated a multivariate effect of the informant on chronic-generic HrQoL, Wilks' Lambda $=.95, F_{(6,258)}=2.13, p=.05$, and on psychological problems, Wilks' Lambda $=.96, F_{(2,268)}=5.30, p=.01$. However, as shown in Table 2, no univariate effects reached statistical significance.

The examination of the child-parent discrepancies indicated rates of agreement ranging from $31.2 \%$ (generic $\mathrm{HrQoL}$ ) to $47.3 \%$ (psychological problems). Overall, the parents tended to score pediatric HrQoL lower and psychological problems higher than did the children (Figure I).

\section{Regression analyses explaining the extent of disagreement}

The regression analyses showed that children's age and gender explained only a small portion of the variance in child-parent absolute discrepancies. After controlling for clinical and sociodemographic variables, the family variables explained a significant portion of the variance (Table 3 ). Specifically, better family relationships were negatively associated with the extent of disagreement in HrQoL reports and a greater caregiving burden was positively associated with the extent of disagreement in the reported HrQoL and psychological problems. 
Table 2 | Descriptive statistics, intraclass correlation coefficients, ANCOVA for repeated measures, and absolute and directional discrepancies

\begin{tabular}{|c|c|c|c|c|c|c|c|c|c|}
\hline & \multirow{2}{*}{\multicolumn{2}{|c|}{ Child-report }} & \multirow{2}{*}{\multicolumn{2}{|c|}{ Parent-report }} & \multirow{3}{*}{$I C C^{a}$} & \multirow{2}{*}{\multicolumn{2}{|c|}{$\begin{array}{l}\text { ANCOVA for repeated } \\
\text { measures }\end{array}$}} & \multicolumn{2}{|c|}{ Discrepancy } \\
\hline & & & & & & & & Absolute ${ }^{c}$ & Directional $^{\mathrm{d}}$ \\
\hline & $M(S D)$ & $\alpha$ & $M(S D)$ & $\alpha$ & & $F$ & $p$ & $M(S D)$ & $M(S D)$ \\
\hline Generic HrQoL & $4.26(0.55)$ & .80 & $4.01(0.57)$ & .78 & .38 & 0.23 & .63 & $0.79(0.4 \mathrm{I})$ & $0.26(0.60)$ \\
\hline Chronic-generic HrQoL & $4.25(0.48)$ & .91 & $4.21(0.49)$ & .93 & .47 & 0.72 & .40 & $0.77(0.34)$ & $0.05(0.50)$ \\
\hline Independence & $4.23(0.58)$ & .73 & $4.31(0.57)$ & .77 & .33 & 2.76 & .10 & $0.72(0.45)$ & $-0.08(0.66)$ \\
\hline Emotion & $4.26(0.7 \mathrm{I})$ & .86 & $4.22(0.73)$ & .91 & .37 & 0.94 & .33 & $0.80(0.54)$ & $0.05(0.8 \mathrm{I})$ \\
\hline Social inclusion & $4.26(0.58)$ & .64 & $4.22(0.59)$ & .70 & .32 & 2.88 & .09 & $0.81(0.45)$ & $0.03(0.68)$ \\
\hline Social exclusion & $4.66(0.48)$ & .71 & $4.60(0.53)$ & .81 & .41 & 0.23 & .63 & $0.47(0.50)$ & $0.06(0.54)$ \\
\hline Physical limitation & $3.87(0.65)$ & .68 & $3.70(0.67)$ & .77 & .41 & $<0.01$ & .96 & $0.89(0.47)$ & $0.17(0.7 I)$ \\
\hline Treatment & $4.16(0.81)$ & .81 & $4.14(0.79)$ & .84 & .36 & 2.75 & .10 & $0.91(0.62)$ & $0.04(0.91)$ \\
\hline Psychological problems & $0.53(0.25)$ & .75 & $0.59(0.30)$ & .81 & .40 & 0.07 & .79 & $0.49(0.19)$ & $-0.06(0.30)$ \\
\hline Internalizing & $0.47(0.28)$ & .62 & $0.52(0.34)$ & .71 & .37 & 2.39 & .12 & $0.50(0.23)$ & $-0.05(0.35)$ \\
\hline Externalizing & $0.58(0.34)$ & .75 & $0.66(0.38)$ & .78 & .46 & 3.48 & .06 & $0.49(0.24)$ & $-0.08(0.37)$ \\
\hline
\end{tabular}

${ }^{a}$ Intraclass correlation coefficients reference values: ICC $<.40=$ poor agreement, ICC between .41 and $.60=$ moderate agreement, ICC between .6I and .80 $=$ good agreement, ICC >.8I = excellent agreement (Landis \& Koch, 1977). All ICCs were statistically significant at the .0I level. ${ }^{b}$ Univariate analyses of covariance for repeated measures, entering the informant (child vs. parent) as the within-subject factor and the socio-demographic and clinical variables (children's age and gender, parents' gender, asthma severity and time since diagnosis) as covariates. ' $\Sigma$ (| child score - parent score |) / number of items for each dimension. ${ }^{\text {d }} \Sigma$ (child score - parent score) / number of items for each dimension. 


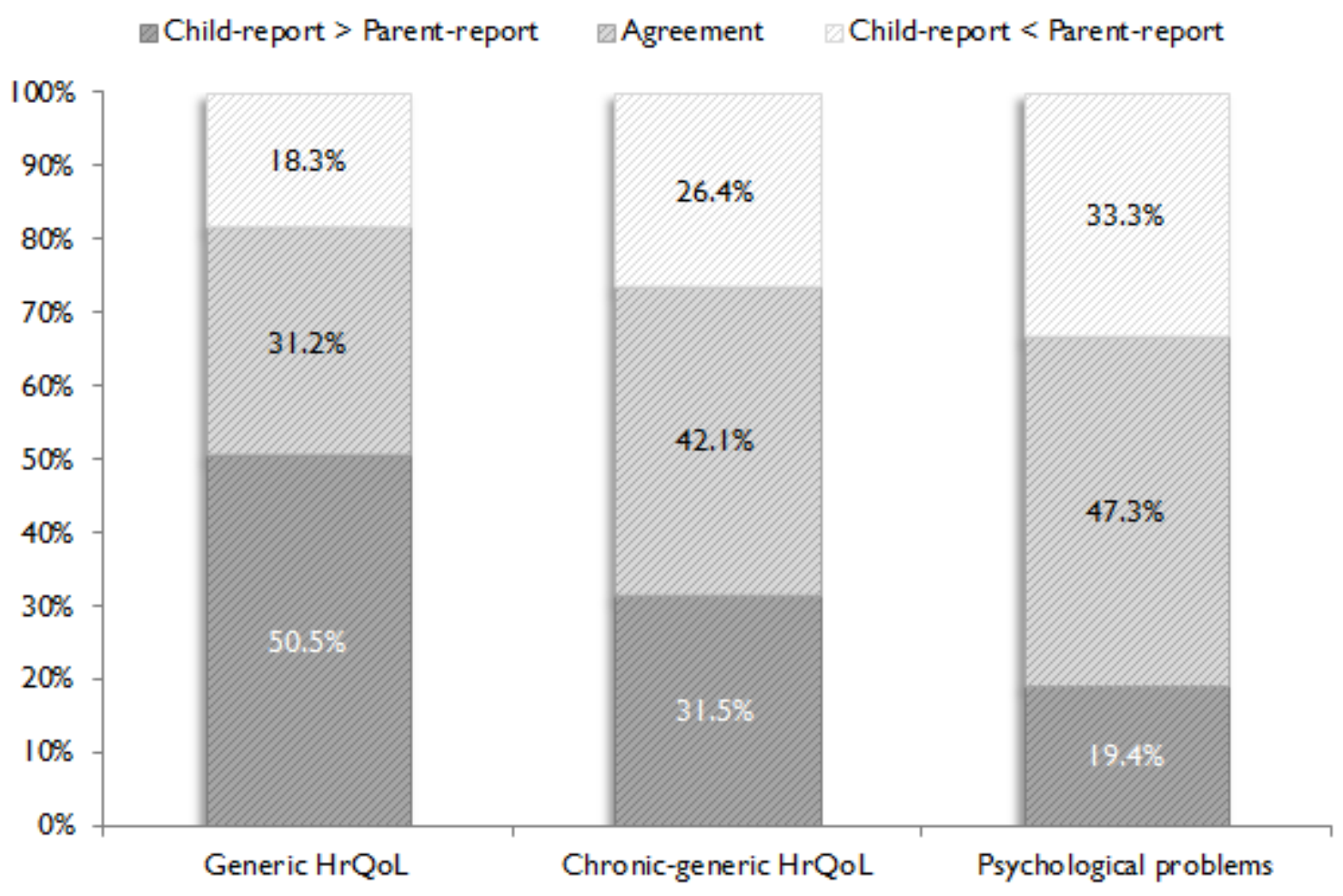

Figure I | Distribution of child-parent directional discrepancies on generic HrQoL, chronic-generic HrQoL and psychological problems

Note. Agreement was defined as an absolute difference between the child's and parent's scores that was lower than or equal to half of the SD of the score with the greatest variability.

Regression analyses explaining the direction of disagreement

The results from the multinomial logistic regression analyses examining "child-report > parent-report" and "child-report < parent-report" vs. "agreement" are presented in Table 4. The socio-demographic and clinical variables were not significantly associated with the direction of disagreement. A greater caregiving burden was associated with an increased likelihood of disagreement in both directions: parents' overrating of generic HrQoL and psychological problems and children's overrating of chronic-generic HrQoL. Family relationships had varying associations with the direction of disagreement: when children perceived less positive family relationships, they were more likely to report worse HrQoL and more psychological problems than their parents; when parents perceived less positive family relationships, they reported worse HrQoL; and when parents perceived better family relationships, they reported fewer psychological problems than the children. 
Table 3 | Hierarchical regression model explaining the extent of the child-parent discrepancies

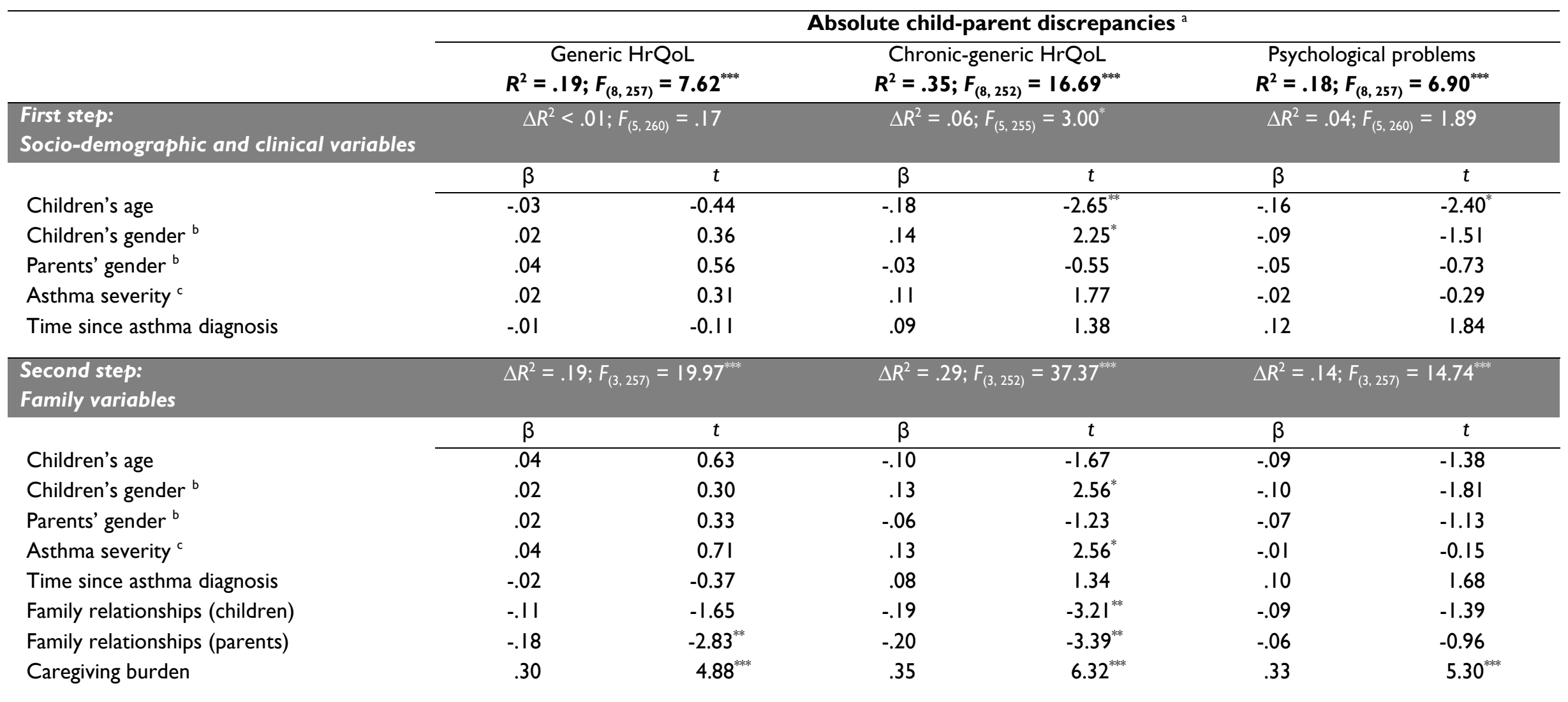

${ }^{a}$ Hierarchical multiple regression analyses, entering the clinical and socio-demographic variables in the first block and the family variables in the second block of the regression equation. ${ }^{b}$ Reference group: $0=$ male; ${ }^{c}$ Reference group: $0=$ intermittent asthma.

$p<.001$, two-tailed. ${ }^{* *} p<.01$, two-tailed. ${ }^{*} p<.05$, two-tailed. 
Table 4 | Multinomial logistic regression model explaining the direction of the child-parent discrepancies

\begin{tabular}{|c|c|c|c|c|c|c|}
\hline & \multicolumn{6}{|c|}{ Directional child-parent discrepancies $^{\text {a }}$} \\
\hline & \multicolumn{2}{|c|}{$\begin{array}{c}\text { Generic HrQoL } \\
R_{(\text {Cox \& Snell) }}^{2}=.13 ; R_{(\text {Nagelkerk) }}^{2}=.14 \\
\text { Model } \chi_{(16)}^{2}=35.60^{* *}\end{array}$} & \multicolumn{2}{|c|}{$\begin{array}{c}\text { Chronic-generic HrQoL } \\
R_{(\text {Cox \& Snell) }}^{2}=.24 ; R_{(\text {Nagelkerke) }}^{2}=.27 \\
\text { Model } \chi_{(16)}^{2}=69.85^{* * *}\end{array}$} & \multicolumn{2}{|c|}{$\begin{array}{c}\text { Psychological problems } \\
R_{(\text {Cox \& Snell) }}^{2}=.12 ; R_{(\text {Nagelkerk) }}^{2}=.14 \\
\text { Model } \chi_{(16)}^{2}=35.28^{* * *}\end{array}$} \\
\hline & $B(\mathrm{SE})$ & Odds Ratio & $B(\mathrm{SE})$ & Odds Ratio & $B(\mathrm{SE})$ & Odds Ratio \\
\hline \multicolumn{7}{|c|}{ Child-report < Parent-report vs. Agreement } \\
\hline Children's age & $.03(.08)$ & I.03 (0.88/ I.2I) & $-.14(.07)$ & 0.87 (0.75/ I.00) & $-.03(.07)$ & $0.97(0.85 / 1.10)$ \\
\hline Children's gender ${ }^{b}$ & $.04(.38)$ & $\mathrm{I} .04(0.49 / 2.20)$ & $-.32(.33)$ & $0.73(0.38 / 1.39)$ & $.07(.30)$ & $1.07(0.60 / 1.93)$ \\
\hline Parents' gender ${ }^{b}$ & $.68(.47)$ & $1.98(0.79 / 4.98)$ & $.52(.42)$ & $1.69(0.74 / 3.84)$ & $-.68(.46)$ & $0.5 \mathrm{I}(0.2 \mathrm{I} / \mathrm{I} .26)$ \\
\hline Asthma severity ${ }^{c}$ & $.05(.38)$ & $1.05(0.50 / 2.20)$ & $.20(.32)$ & $1.22(0.65 / 2.29)$ & $.23(.29)$ & $1.25(0.7 \mid / 2.22)$ \\
\hline Time since asthma diagnosis & $-.07(.05)$ & $0.93(0.85 / 1.03)$ & $.03(.04)$ & $1.03(0.95 / 1.12)$ & $.04(.04)$ & $1.04(0.97 / 1.13)$ \\
\hline Family relationships (children) & $-.65(.32)^{*}$ & $0.52(0.28 / 0.99)$ & $-.84(.29)^{* *}$ & $0.43(0.25 / 0.76)$ & $.45(.26)$ & $1.56(0.94 / 2.60)$ \\
\hline Family relationships (parents) & $.40(.39)$ & $1.49(0.69 / 3.20)$ & $-.08(.31)$ & $0.93(0.50 / \mathrm{I} .7 \mathrm{I})$ & $-.35(.28)$ & $0.70(0.4 \mathrm{I} / \mathrm{I} .2 \mathrm{I})$ \\
\hline Caregiving burden & $.61(.30)^{*}$ & $1.84(1.02 / 3.35)$ & $.31(.28)$ & $1.36(0.78 / 2.37)$ & $.51(.23)^{*}$ & $1.66(1.06 / 2.60)$ \\
\hline \multicolumn{7}{|c|}{ Child-report > Parent-report vs. Agreement } \\
\hline Children’s age & $.03(.07)$ & I.03 (0.90/ I.I7) & $-.01(.08)$ & $0.99(0.86 / \mathrm{I} .15)$ & $-.15(.08)$ & $0.86(0.74 / 1.00)$ \\
\hline Children's gender ${ }^{b}$ & $.29(.30)$ & $\mathrm{I} .33(0.74 / 2.39)$ & $-.34(.34)$ & $0.7 \mid(0.37 /$ I.37) & $-.25(.35)$ & $0.78(0.39 / 1.56)$ \\
\hline Parents' gender ${ }^{b}$ & $-.64(.43)$ & $0.53(0.23 / 1.23)$ & $-.75(.54)$ & $0.47(0.17 / 1.35)$ & $.58(.44)$ & $1.79(0.75 / 4.25)$ \\
\hline Asthma severity ${ }^{c}$ & $-.28(.29)$ & $0.75(0.43 /$ I.34) & $-.09(.33)$ & $0.92(0.48 / \mathrm{I} .75)$ & $-.22(.34)$ & $0.80(0.4 \mathrm{I} / \mathrm{I} .57)$ \\
\hline Time since asthma diagnosis & $-.04(.04)$ & $0.96(0.89 / 1.04)$ & $-.02(.04)$ & $0.98(0.90 / 1.07)$ & $.03(.05)$ & $1.03(0.94 / 1.13)$ \\
\hline Family relationships (children) & $.32(.26)$ & $\mathrm{I} .38(0.83 / 2.29)$ & $.53(.30)$ & $1.70(0.95 / 3.06)$ & $-.77(.30)^{*}$ & $0.47(0.26 / 0.83)$ \\
\hline Family relationships (parents) & $-.76(.29)^{*}$ & $0.47(0.26 / 0.83)$ & $-.69(.32)^{*}$ & $0.50(0.27 / 0.94)$ & $.84(.36)^{*}$ & $2.32(1.15 / 4.7 I)$ \\
\hline Caregiving burden & $.41(.24)$ & $\mathrm{I} .50(0.94 / 2.4 \mathrm{I})$ & $1.35(.28)^{* * * *}$ & $3.85(2.23 / 6.65)$ & $.26(.28)$ & $1.29(0.75 / 2.24)$ \\
\hline
\end{tabular}

a Multinomial logistic regression analyses, using "agreement" as the reference category and entering the child's and parent's genders and the child's asthma severity as categorical factors and the child's age, time since diagnosis and family factors as covariates. ${ }^{b}$ Reference group: $0=$ male; ' Reference group: $0=$ intermittent asthma.

"** $p<.001$, two-tailed. ${ }^{* *} p<.01$, two-tailed. ${ }^{*} p<.05$, two-tailed. 


\section{Discussion}

To our knowledge, this is the first study examining the role of family relationships and caregiving burden in explaining the extent and direction of child-parent (dis)agreement. Three main findings should be considered. First, most of the children with asthma and their parents differed in their perceptions of pediatric adaptation outcomes. Second, although disagreement occurred in both directions, the parents were more likely to report worse HrQoL and more psychological problems than the children. Finally, the extent and direction of disagreement were better explained by familyrelated factors than by socio-demographic and clinical variables. The strengths of this research include the use of developmentally appropriate instruments for assessing $\mathrm{HrQoL}$ and psychological problems with strictly parallel versions for children and parents and the adoption of a multiinformant approach; both children and parents reported on family relationships, and the physicians reported on asthma severity.

The low to moderate levels of agreement found at the individual level confirmed our first hypothesis and coincide with previous studies (e.g., Ender et al., 20II; White-Koning et al., 2007). These results can be understood within a cognitive-developmental framework, which suggests that children and adults differ in their understanding of the concept of illness, its causes and the effects of treatment (Bibace \& Walsh, 1980). Although the instruments used to assess children's adaptation outcomes have been semantically and psychometrically validated for children as young as $\mathbf{8}$ years and for family caregivers, children and parents may support their answers with different experiences (Davis et al., 2007). At the group level, no significant differences were found between child and parent-reported adaptation outcomes, regardless of the domains being assessed, which refutes the hypothesis raised by Upton and colleagues (2008).

Consistent with most of the previous research conducted with clinical samples (e.g., Becker et al., 2004; Sattoe et al., 2012; White-Koning et al., 2007) and as predicted in our second hypothesis, when disagreement occurred, it was likely to be in the direction of parents reporting worse HrQoL and more psychological problems. These results may reflect, on the one hand, the children's tendency to emphasize the positive aspects of adaptation (Oeffinger et al., 2007). On the other hand, parents may be more reliable in identifying the most strongly affected areas of their children's functioning and the so-called "hidden morbidities" (Varni, Burwinkle, \& Lane, 2005). Therefore, a dyadic child-parent approach to assessing pediatric outcomes may provide unique information about the children's risk factors and resilience.

The extent and direction of child-parent disagreement on adaptation outcomes were primarily explained by family-related factors. Children's and parents' perceptions of less positive family relationships were significantly associated with greater disagreement on HrQoL reports. These findings suggest that a family context that is characterized by high levels of cohesion and low 
levels of conflict, which allows children to openly express their worries and feelings, might be more important in explaining child-parent (dis)agreement than developmental characteristics and communication skills. Regarding the direction of disagreement, we observed a tendency for children and parents underrate the pediatric adaptation outcomes when they also perceived family relationships as less positive. These findings may reflect informant biases, but they could also indicate that individual perceptions of family relationships may affect how each family member evaluates the children's health status. Furthermore, a greater caregiving burden was significantly associated with increased disagreement, regardless of its direction. Parents' perceptions of caregiving tasks and asthma management routines as overly demanding and burdensome have been associated with negative mother-child interactions (Fiese, Winter, Anbar, Howell, \& Poltrock, 2008), which may limit the exchange of information between children and parents. Moreover, the caregiving burden is also likely to negatively affect children's and parents' perceptions of the family environment (Crespo, Carona, Silva, Canavarro, \& Dattilio, 20II) and thus contribute indirectly to child-parent disagreement on adaptation outcomes.

Two main limitations should be acknowledged in the present study. First, the nonprobabilistic sampling strategy may have influenced the levels of agreement because parents who participated were more involved in pediatric healthcare than parents in the general population. In addition, the low frequency of children with severe asthma required the dichotomization of the asthma severity variable and increased the intragroup variability. Furthermore, the sample of caregivers included mostly mothers, which limited the ability to assess the potential role of the caregivers' gender in explaining the extent and direction of child-parent disagreement. Second, the study's cross-sectional design precluded causal inferences among the variables. Given the possibility that the associations between family-related factors and child-parent disagreement are bidirectional, longitudinal studies should further investigate this hypothesis.

Despite the aforementioned limitations, our findings have important implications for pediatric asthma research and clinical practice. The tendency for parents to report worse HrQoL and more psychological problems than children suggests, on the one hand, that parents may underestimate children's abilities to adapt to adverse circumstances and, on the other hand, that they may be more aware of children's current and future functional limitations. Moreover, parents assume important responsibilities in asthma management and healthcare decision making. Childparent disagreement may influence the way parents respond to children's healthcare and emotional needs, which may influence their adaptation over time. Therefore, routine assessment of children's adaptation outcomes should include both children's and parents' perspectives as complementary sources of information and should also consider the family factors that are likely to influence childparent (dis)agreement. The additional cost of conducting a more in-depth assessment of adaptation outcomes can be offset by more efficiently allocating health resources and implementing clinical 
interventions.

\section{Key messages}

- The agreement between children with asthma and their parents on pediatric adaptation outcomes was low to moderate.

- Parents were more likely to report worse pediatric HrQoL and more psychological problems than children themselves.

- Both the extent and direction of child-parent disagreement were better explained by family relationships and caregiving burden than by clinical or socio-demographic variables.

- When possible, information about children's adaptation outcomes should be collected from both children and parents, while also consider the family context.

- An in-depth assessment of pediatric adaptation outcomes can enhance a more efficient allocation of health resources.

\section{References}

Annett, R. D., Bender, B. G., DuHamel, T. R., \& Lapidus, J. (2003). Factors influencing parent reports on quality of life for children with asthma. Journal of Asthma, 40, 577-587. doi:10.108I/JAS120019030

April, K. T., Feldman, D. E., Platt, R. W., \& Duffy, C. M. (2006). Comparison between children with Juvenile Idiopathic Arthritis (IIA) and their parents concerning perceived quality of life. Quality of Life Research, 15, 655-66I. doi:10.1007/s I I 136-005-3690-I

Becker, A., Hagenberg, N., Roessner, V., Woerner, W., \& Rothenberger, A. (2004). Evaluation of the self-reported SDQ in a clinical setting: Do self-reports tell us more than ratings by adult informants? European Child \& Adolescent Psychiatry, 13, 17-24. doi:10.1007/s00787-004-2004-4

Bibace, R., \& Walsh, M. E. (1980). Development of children's concepts of illness. Pediatrics, 66(6), 912-917.

Bullinger, M., Schmidt, S., Peterson, C., \& Ravens-Sieberer, U. (2006). Quality of life: Evaluation criteria for children with chronic conditions in medical care. Journal of Public Health, 14, 343355. doi:10.1007/s 10389-006-0066-0

Carona, C., Crespo, C., Silva, N., Lopes, A. F., Canavarro, M. C., \& Bullinger, M. (20I3). Examining a developmental approach to health-related quality of life assessment: Psychometric analysis of DISABKIDS generic module in a Portuguese sample. Vulnerable Children \& Youth Studies, 8, 243-257. doi:10.1080/17450I28.2012.736647 
Carona, C., Silva, N., \& Canavarro, M. C. (20II, July). Avaliação de dimensões positivas e negativas da prestação de cuidados familiares: Estudos de validação da "Revised Burden Measure" em contextos pediátricos [Assessment of positive and negative dimensions of family caregiving: Validation studies of the "Revised Burden Measure" in pediatric contexts]. In H. Moreira \& M. C. Canavarro (Chair), Avaliação da parentalidade: Construção e desenvolvimento de instrumentos de avaliação. Symposium conducted at the VIII Congresso Iberoamericano de Avaliação Psicológica/XV Conferência Internacional Avaliação Psicológica: Formas e Contextos, Lisboa.

Clarke, S.-A., \& Eiser, C. (2004). The measurement of health-related quality of life (QOL) in paediatric clinical trials: A systematic review. Health and Quality of Life Outcomes, 2, 66. doi:10.1 I86/1477-7525-2-66

Cremeens, J., Eiser, C., \& Blades, M. (2006). Factors influencing agreement between child self-report and parent proxy-reports on the Pediatric Quality of Life Inventory(TM) 4.0. Health and Quality of Life Outcomes, 4, 58. doi:10.1 186/1477-7525-4-58

Crespo, C., Carona, C., Silva, N., Canavarro, M. C., \& Dattilio, F. (20I I). Understanding quality of life in children with asthma and their parents: Family resources and challenges. Journal of Contemporary Family Therapy, 33, 179-196. doi:10.1007/s 10591-01 I-9155-5

Davis, E., Nicolas, C., Waters, E., Cook, K., Gibbs, L., Gosh, A., \& Ravens-Sieberer, U. (2007). Parent-proxy and child self-reported health-related quality of life: Using qualitative methods to explain the discordance. Quality of Life Research, I6, 863-87I. doi:I0.1007/s III36-007$9187-3$

de Civita, M., Regier, D., Alamgir, A. H., Anis, A. H., Fitzgerald, M. J., \& Marra, C. A. (2005). Evaluating health-related quality-of-life studies in paediatric populations: Some conceptual, methodological and developmental considerations and recent applications. Pharmacoeconomics, 23(7), 659-685.

Eiser, C., \& Morse, R. (200I). Can parents rate their child's health-related quality of life? Results of a systematic review. Quality of Life Research, 10, 347-357. doi:I0.1023/A:I012253723272

Ender, S., Stachow, R., Petermann, F., \& Tiedjen, U. (20II). Verhaltensauffälligkeiten bei körperlich chronisch kranken jugendlichen: Übereinstimmungen und unterschiede im selbst-und elternurteil [Behavioral problems of somatic chronically ill adolescents: Parent-childagreement and differences]. Klinische Pädiatrie, 223, 23I-235. doi:10.1055/s-0030-1269863

Field, A. (2009). Discovering statistics using SPSS (3rd ed.). London, UK: Sage.

Fiese, B., Winter, M., Anbar, R., Howell, K., \& Poltrock, S. (2008). Family climate of routine asthma care: Associating perceived burden and other-child interaction patterns to child well-being. Family Process, 47, 63-79. doi:10.1 II I/j.1545-5300.2008.00239.x

Fleitlich, B., Loureiro, M., Fonseca, A., \& Gaspar, M. F. (2005). Questionário de Capacidades e de 
Dificuldades (SDQ-Por) [Strengths and Difficulties Questionnaire - Portuguese version]. Retrived from http://www.sdqinfo.org

Gaspar, A., Almeida, M. M., \& Nunes, C. (2006). Epidemiologia da asma grave [Epidemiology of severe asthma]. Revista Portuguesa de Imunoalergologia, I4(S2), 27-4I.

Gaspar, T., Matos, M. G., Batista-Foguet, J., Pais-Ribeiro, J. L., \& Leal, I. (2010). Parent-child perceptions of quality of life: Implications for health intervention. Journal of Family Studies, 16(2), I43-154.

Global Initiative for Asthma. (2008). Global strategy for asthma management and prevention - updated 2008. Retrieved from http://www.ginasthma.org

Goodman, R. (200I). Psychometric properties of Strengths and Difficulties Questionnaire. Journal of the American Academy of Child \& Adolescent Psychiatry, 40, 1337-1345. doi:10.1097/00004583$200111000-00015$

Goodman, A., Lamping, D. L., \& Ploubidis, G. B. (20/0). When to use broader internalising and externalising subscales instead of the hypothesised five subscales on the Strengths and Difficulties Questionnaire (SDQ): Data from British parents, teachers and children. Journal of Abnormal Child Psychology, 38, II79-II9I. doi:10.1007/s 10802-010-9434-x

Jokovic, A., Locker, D., \& Guyatt, G. (2004). How well do parents know their children? Implications for proxy reporting of child health-related quality of life. Quality of Life Research, 13, 1297 | 307. doi:10.1023/B:QURE.0000037480.65972.eb

Kenny, D. A., Kashy, D. A., \& Cook, W. L. (2006). Dyadic data analysis. New York, NY: Guilford.

Landis, J. R., \& Koch, G. G. (1977). The measurement of observer agreement for categorical data. Biometrics, 33(I), I59-174.

le Coq, E. M., Boeke, A. J. P., Bezemer, P. D., Colland, V. T., \& van Eijk, J. Th. M. (2000). Which source should we use to measure quality of life in children with asthma: The children themselves or their parents? Comparing the psychometric properties of a child- and a parent- report scale. Quality of Life Research, 9, 625-636. doi:10.1023/A:1008977200I76

Matos, M. G., Gaspar, T., \& Simões, C. (2012). Health-related quality of life in Portuguese children and adolescents. Psicologia: Reflexão e Crítica, 25, 230-237. doi:10.1590/S010279722012000200004

Matza, L. S., Swensen, A. R., Flood, E. M., Secnik, K., \& Leidy, N. K. (2004). Assessment of healthrelated quality of life in children: A review of conceptual, methodological and regulatory issues. Value in Health, 7, 79-92. doi:10.1 I I I/j.1524-4733.2004.7। 273.x

Montgomery, R., \& Kosloski, K. (2006). The league of experienced family caregivers: Measure development. Milwaukee, WI: University of Wisconsin-Milwaukee.

Moos, R. H. (1990). Conceptual and empirical approaches to developing family-based assessment procedures: Resolving the case of the Family Environment Scale. Family Process, 29, 199-208. 
doi:10.1 III/j.1545-5300.1990.00199.x

Moos, R. H., \& Moos, B. (1986). Family Environment Scale manual (2nd ed.). Palo Alto, CA: Consulting Psychologists Press.

Norman, G. R., Sloan, J. A., \& Wyrwich, K. W. (2003). Interpretation of changes in health-related quality of life: The remarkable universality of half a standard deviation. Medical Care, 4I(5), $582-592$.

Oeffinger, D., Gorton, G., Bagley, A., Nicholson, D., Barnes, D., Calmes, J., ... Tylkowski, C. (2007). Outcome assessments in children with cerebral palsy, part I: Descriptive characteristics of GMFCS Levels I to III. Developmental Medicine \& Child Neurology, 49, I72-I80. doi:I0.I I I I/j.I469-8749.2007.00I72.x

Petsios, K., Priftis, K. N., Tsoumakas, C., Hatziagorou, E., Tsanakas, J. N., Galanis, P., Antonogeorgos, G., \& Matziou, V. (20II). Level of parent-asthmatic child agreement on health-related quality of life. Journal of Asthma, 48, 286-297. doi:10.3109/02770903.20II.55503।

Ravens-Sieberer, U., Erhart, M., Rajmil, L., Herdman, M., Auquier, P., Bruil, J., ... The European KIDSCREEN Group. (2010). Reliability, construct and criterion validity of the KIDSCREEN10 score: A short measure for children and adolescents' well-being and health-related quality of life. Quality of Life Research, 19, I487-1500. doi:10.1007/s I | 36-010-9706-5

Russell, K. M. W., Hudson, M., Long, A., \& Phipps, S. (2006). Assessment of health-related quality of life in children with cancer: Consistency and agreement between parent and child reports. Cancer, 106, 2267-2274. doi:10.1002/cncr.2187|

Sattoe, J. N. T., van Staa, A., \& Moll, H. A. (20/2). The proxy problem anatomized: Child-parent disagreement in health related quality of life reports of chronically ill adolescents. Health and Quality of Life Outcomes, 10, 10. doi:10.1 I86/1477-7525-10-10

Sawyer, M. G., Baghurst, P., \& Mathias, J. (1992). Differences between informants' reports describing emotional and behavioural problems in community and clinic-referred children: A research note. Journal of Child Psychology and Psychiatry, 33, 44I-449. doi:I0.1III/j.14697610.1992.tb00878.x

Simões, M. R. (1994). Investigações no âmbito da aferição nacional do teste das Matrizes Progressivas de Raven. Unpublished Doctoral Dissertation. Universidade de Coimbra. Coimbra, Portugal.

Sneeuw, K. C., Sprangers, M. A., \& Aaronson, N. K. (2002). The role of health care providers and significant others in evaluating the quality of life of patients with chronic disease. Journal of Clinical Epidemiology, 55, I I30-I I 43. doi:I0.1016/S0895-4356(02)00479-I

The DISABKIDS Group Europe (2006). The DISABKIDS questionnaires: Quality of life questionnaires for children with chronic conditions - Handbook. Lengerich: Pabst Science Publishers.

Theunissen, N. C. M., Vogels, T. G. C., Koopman, H. M., Verrips, G. H. W., Zwinderman, K. A. H., Verloove-Vanhorick, S. P., \& Wit, J. M. (1998). The proxy problem: Child report versus 
parent report in health-related quality of life research. Quality of Life Research, 7, 387-397. doi: 10.1023/A:1008801802877

Upton, P., Lawford, J., \& Eiser, C. (2008). Parent-child agreement across child health-related quality of life instruments: A review of the literature. Quality of Life Research, 17, 895-913. doi:|0.1007/s| ||36-008-9350-5

van der Meer, M., Dixon, A., \& Rose, D. (2008). Parent and child agreement on reports of problem behaviour obtained from a screening questionnaire, the SDQ. European Child \& Adolescent Psychiatry, I7, 49I-497. doi:10.1007/s00787-008-069I-y

van Roy, B., Groholt, B., Heyerdahl, S., \& Clench-Aas, J. (2010). Understanding discrepancies in parent-child reporting of emotional and behavioural problems: Effects of relational and sociodemographic factors. BMC Psychiatry, 10, 56. doi:I0.1 I86/I47/-244X-10-56

Varni, J. W., Burwinkle, T. M., \& Lane, M. M. (2005). Health-related quality of life measurement in pediatric clinical practice: An appraisal and precept for future research and application. Health and Quality of Life Outcomes, 3, 34. doi:10.1 186/1477-7525-3-34

Wallander, J. L., Schmitt, M., \& Koot, H. M. (200I). Quality of life measurement in children and adolescents: Issues, instruments, and applications. Journal of Clinical Psychology, 57, 57I-585. doi:10.1002/jclp.1029

White-Koning, M., Arnaud, C., Dickinson, H. O., Thyen, U., Beckung, E., Fauconnier, J., ... Colver, A. (2007). Determinants of child-parent agreement in Quality-of-Life reports: A European study of children with cerebral palsy. Pediatrics, I20, 804-8I4. doi:10.1542/peds.2006-3272

World Health Organization. (1993). Measurement of quality of life in children: Report of a WHO/ IACAPAP working party. Geneva: Author. 